\title{
System model for spatial mapping of anthropogenic sinkholes and subsidence basins in mining areas applying 2D laser scanner technique
}

\author{
Zbigniew Motyka ${ }^{1, *}$, Bjørn Petter Jelle ${ }^{2,3}$, \\ ${ }^{1}$ Główny Instytut Górnictwa, Katowice, Poland \\ ${ }^{2}$ Norwegian University of Science and Technology (NTNU), Trondheim, Norway \\ ${ }^{3}$ SINTEF Building and Infrastructure, Trondheim, Norway
}

\begin{abstract}
The model of a remote measurement system suitable for use on mobile unmanned aerial platforms is discussed in order to provide data for mapping spatial parameters of anthropogenic landscape forms, mainly outcrops, sinkholes, subsidence basins around urbanized industrial areas, especially those covered by past and ongoing mining activities. The results of the tests carried out with the use of a prototype model of such system are presented. These show that for the model forming small depression in terrain, its visualization was possible enabling obtaining its true geometrical characteristics.
\end{abstract}

Keywords: laser scanner, photogrammetry, remote sensing, model, UAV, anthropogenic forms, mining areas, outcrops, sinkholes, subsidence basins

\section{Introduction}

In urbanized industrial areas, especially those covered by the ongoing or past mining activities, whether for opencast mines (surface excavations) or underground mines, as well as in non-agricultural and agricultural areas, we encounter intentional (excavation) or accidental results everywhere (depressions, subsidence basins) of anthropogenic (manmade) influences on landscape forms. It is important to maintain a balanced approach to anthropogenic landscape changes accompanying human economical activities, including restoring the landscape's natural values close to all those places where such activities have ceased (landscape restoration, nature revitalization). Thus, a detailed inventory is necessary (photographic documentation, mapping, including spatial) of such variables in time and space of anthropogenic landscape forms and plant formations [1-7].

\footnotetext{
* Corresponding author: zmotyka@gig.eu
} 
For anthropogenic formations on uncultivated land, open pits, pit traps and subsidence basins associated with current and past mining activities can be included. For their location, the Upper Silesian System of Information on Surface Dangers on the Terrains of Closed Mines may be used [7] (Fig.1a).

The objective of the study presented herein is to develop model of laser system which could be used in the future on an unmanned aerial vehicle (UAV) in aims of obtaining geometrical characteristics of similar anthropogenic landscape forms. The model was built and its laboratory tests were carried out, including the use of small model terrain depression as a model object of subsidence basin. These show that for the chosen model of such subsidence, forming a true small depression in terrain, its visualization was possible enabling obtaining its true geometrical characteristics.

\section{A remote laser system for determining the geometrical parameters of mining terrain subsidence from low altitudes}

The area is currently being laser scanned by using laser lidars (light detection and ranging) applying a pulsed laser scanning environment and measuring the time-of-flight (TOF) of the scattered optical pulse. The lidars can be used to determine distances from 1 meter to many kilometers. To increase their range, very short radiation pulses from the near infrared (NIR) range are utilized. Much more accurate than them, 2D and 3D laser scanners are which use a lower power continuous modulated laser beam and a phase distance measurement typical of laser rangefinders. Due to the lower power of the beam, they allow the measurement of much smaller distances (up to several dozen meters) [8-12].

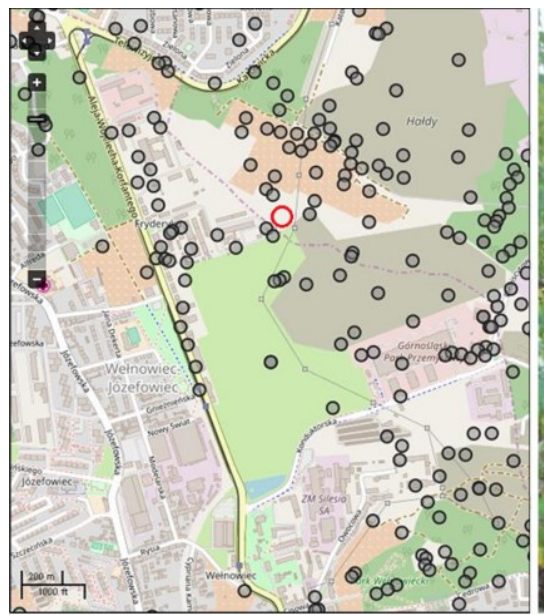

(a)

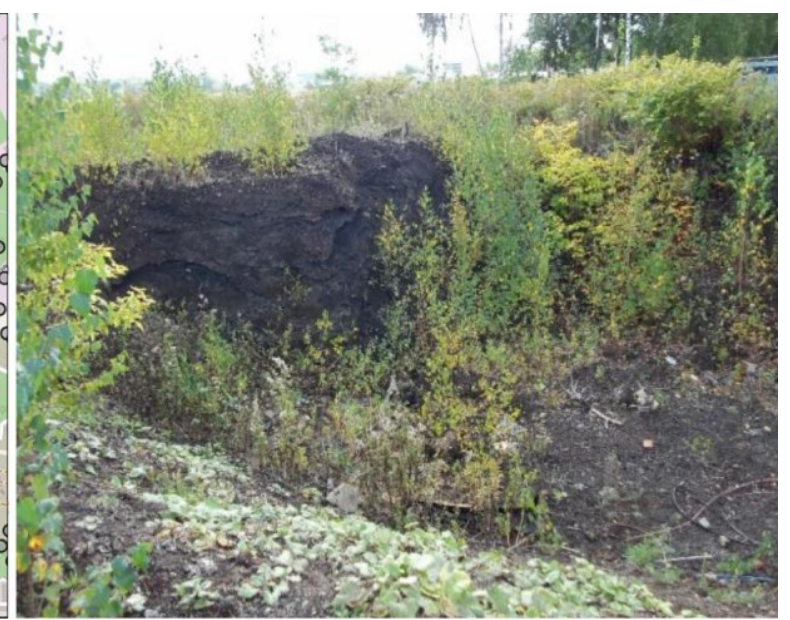

(b)

Fig. 1. Outskirts of Katowice: A map (a) with points of past mining operations. Red circle denotes one of test sites with a real mining sinkhole (b). 


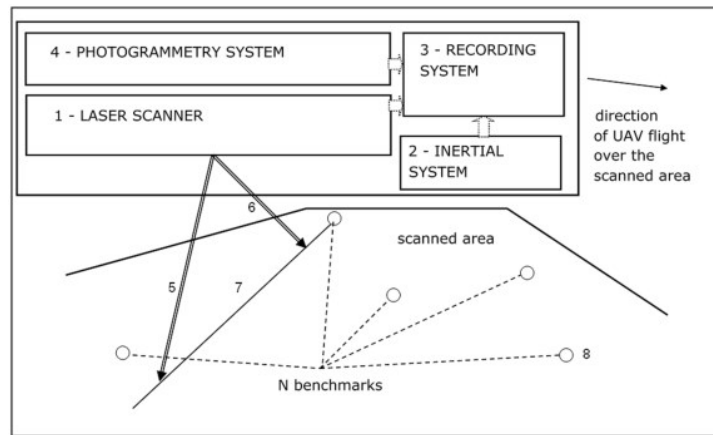

(a)

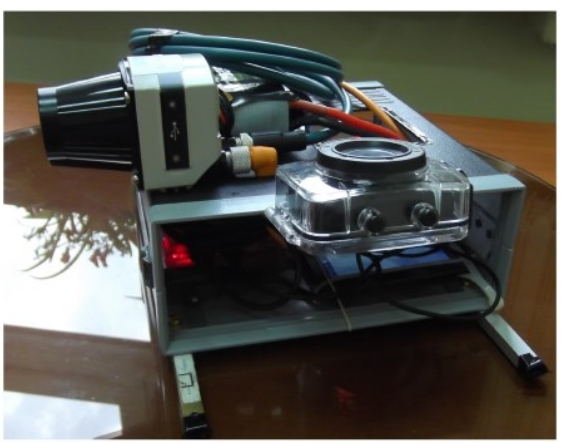

(b)

Fig. 2. System diagram (a) and prototype (b) of photogrammetry and remote laser determining the geometry of the anthropogenic forms of land. The laser beam in the extreme positions 5 and 6 sweeps line 7 on the surface during the UAV platform flight over it. In the case of periodic inspection in the area, there can be distinguished a series of natural or artificially introduced benchmarks 8 .

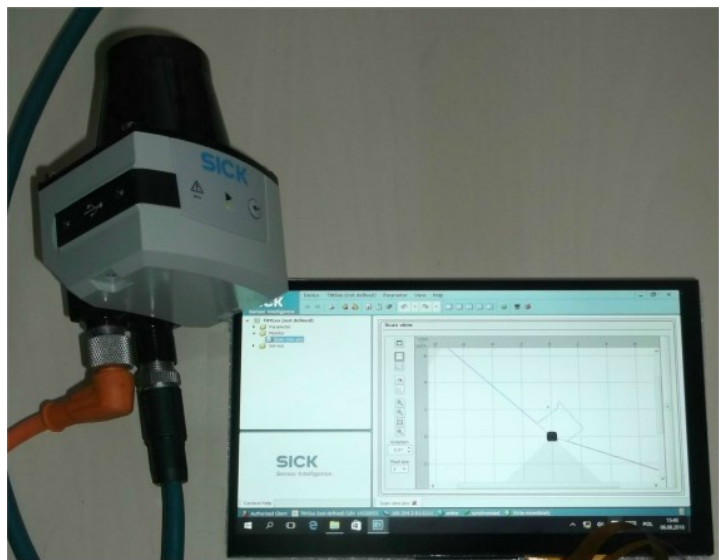

(a)

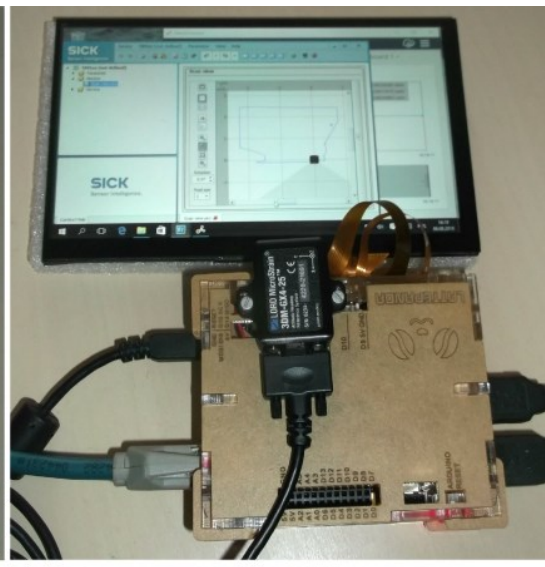

(b)

Fig. 3. A set of three basic elements being tested within the model of system for remote laser scanning of terrain: (a) typical laser scanner 2D, (b) inertial system with a recorder system of $64 \mathrm{~GB}$ RAM memory running under Windows 10.

Fig.2 shows the scheme of the system for photogrammetry and remote laser determination of geometrical parameters of anthropogenic landscape forms and plant formations, based on a $2 \mathrm{D}$ laser scanner cooperating with an inertial position sensor. In Fig. 3 the first three elements of the tested equipment from Fig.2a are collected.

\section{Laboratory scale tests of 2D laser scanning system components}

Figs. 4-8 illustrate the tests on a laboratory scale and their results on the example of laboratory rooms, and at external conditions for a small model of the sinkhole and for the field test site from Fig.1. Fig.4 presents an example of scans obtained using 2D laser scanner at laboratory conditions for a ceiling of a long stretch of the corridor, with the help of own software in Delphi 5.0. 


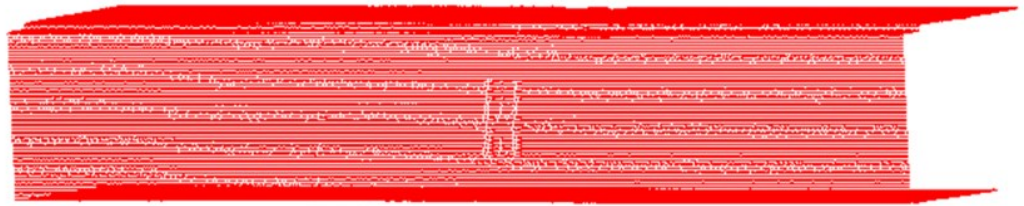

Fig. 4. Example of scan obtained using 2D laser scanner at laboratory conditions for a ceiling of a long stretch of the corridor. The image was obtained with the use of own software in Delphi 5.0

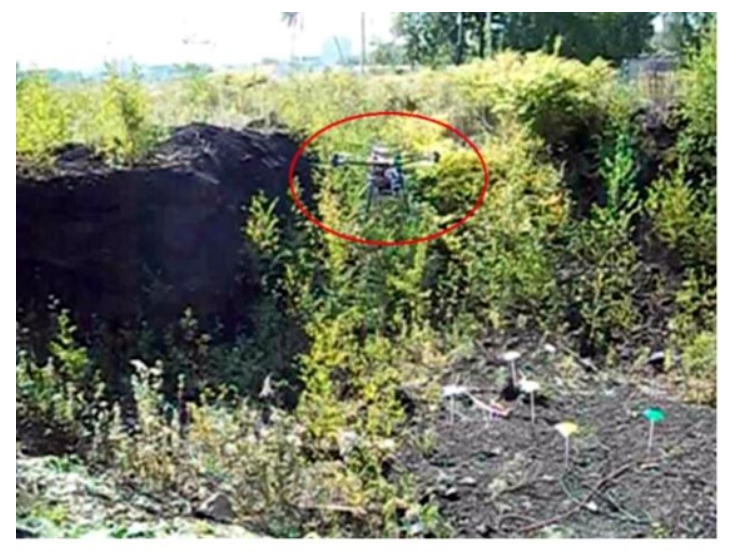

(a)

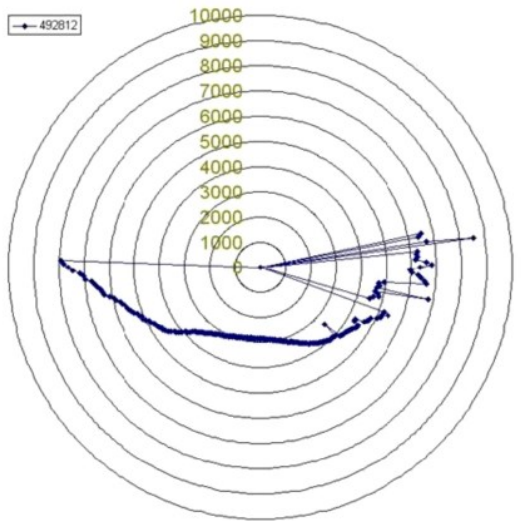

(b)

Fig. 5. The developed in GIG laser mining scanner during field tests with the use of UAV platform (in red oval) (a), and an example of a single 2D scan of a mining sinkhole, obtained using this system solution (b).

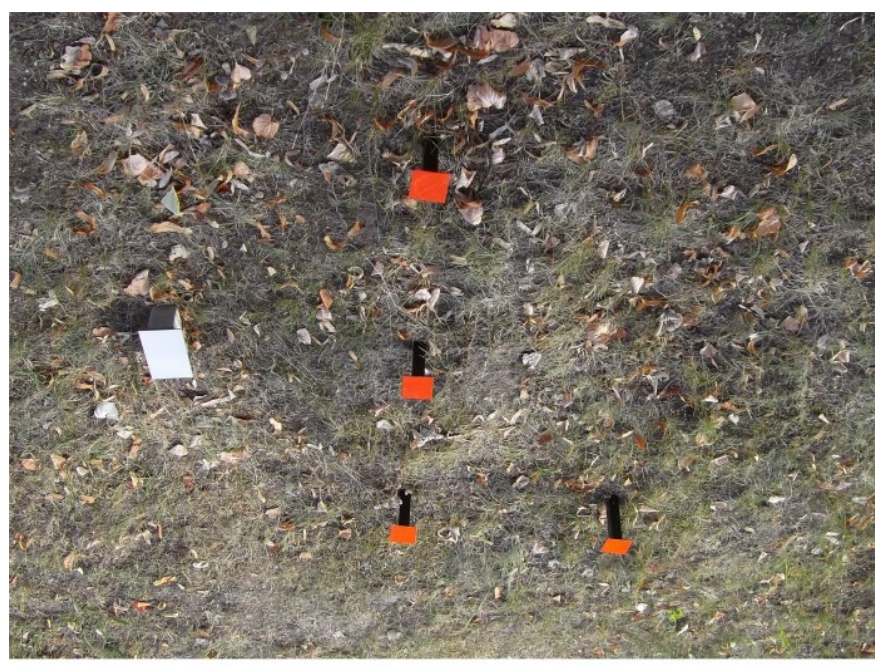

(a)

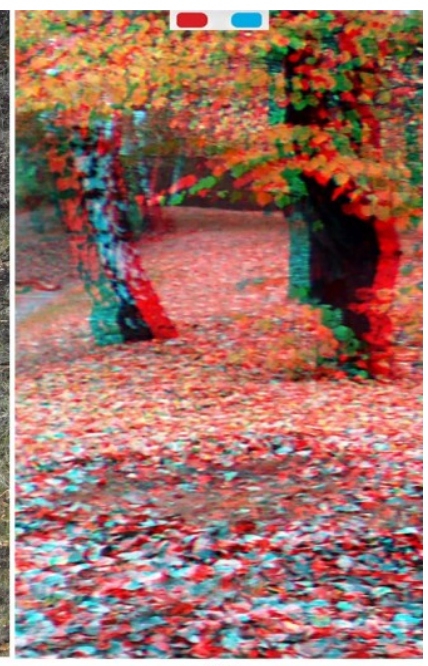

(b)

Fig. 6. The external tests configuration when measuring the model of shallow cavity geometry using a 2D laser scanner (a) with its later general stereoscopic view (b). 
At Fig.5 the developed in GIG laser mining scanner during field tests with the use of UAV platform was presented together with an example of a single 2D scan of a mining sinkhole from Fig.1b, obtained using this system solution.

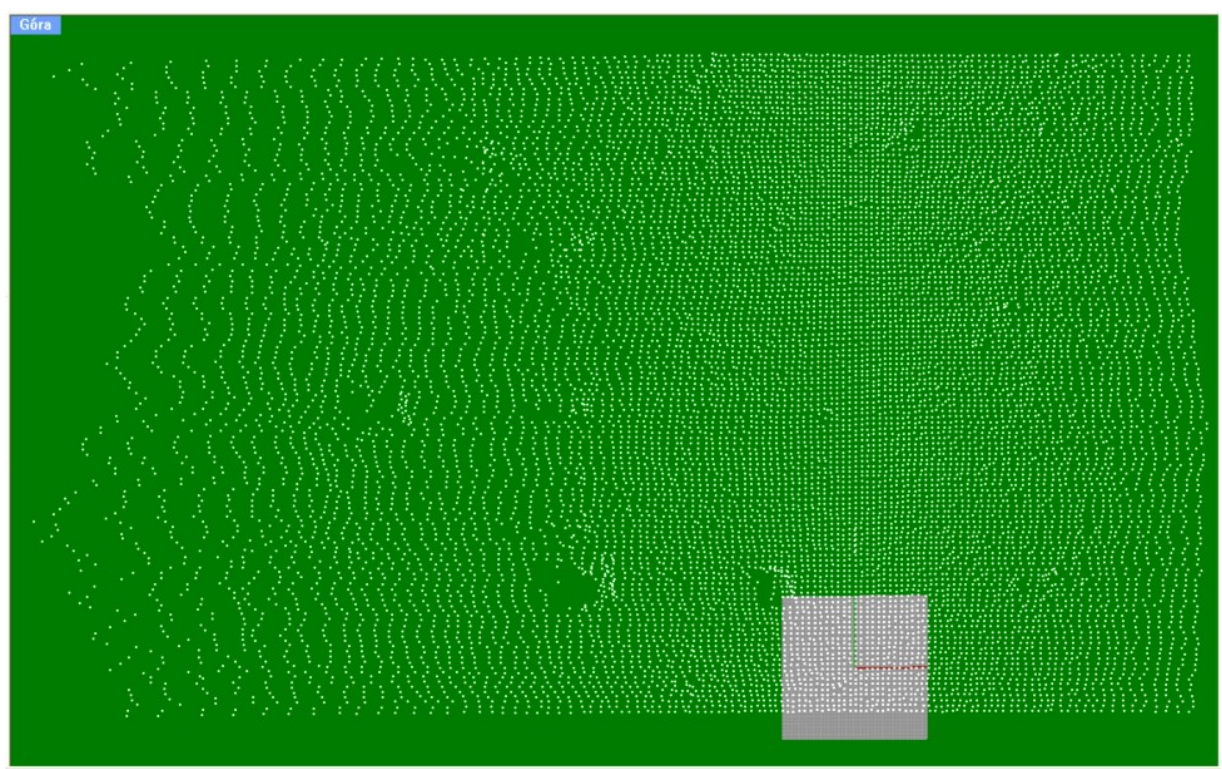

Fig. 7. An example of obtained results for external testing of the 2D laser scanner system.

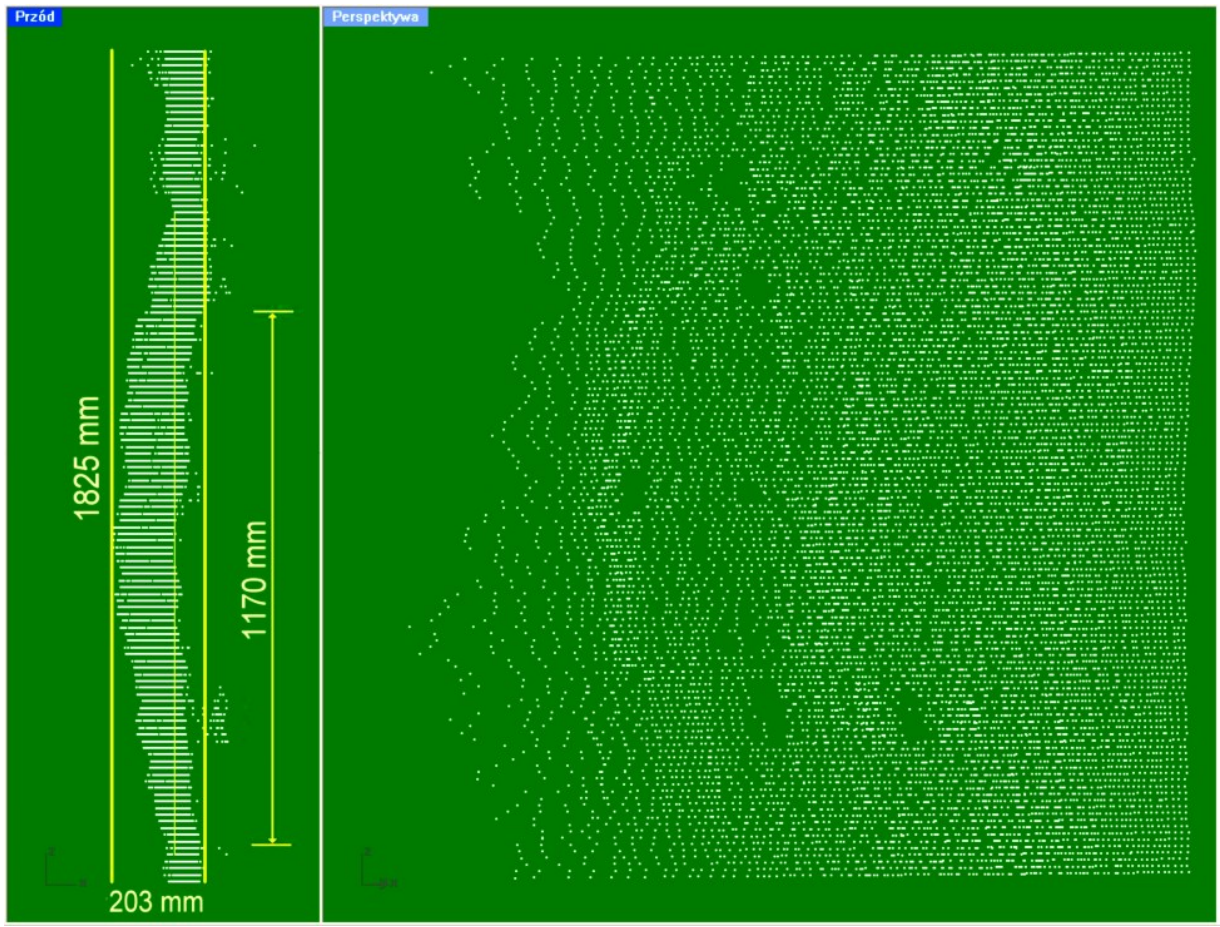

Fig. 8. An example of obtained analysis results for external testing of the 2D laser scanner system. 
Fig.6 presents the external tests configuration when measuring the model of shallow cavity geometry using a 2D laser scanner, and at Fig. 7 the resultant cloud of points obtained with the use of tested 2D laser scanner system was visualized with the help of Rhino 4 software.

Fig.8 presents an example of obtained from analysis of this cloud of points results presenting the chosen true geometrical parameters of tested small sinkhole model, including its depth and diameter. These remain in a good agreement with control measurements.

\section{Summary}

A series of registration was obtained of various anthropogenic forms, up to the model of a shallow hollow subsidence, with the aim for future applications for former mining areas. Herein, there is the possibility of recognizing the types of geotechnical objects and subsidence formation parameters with the use of UAV systems from a small height. This technique confirmed its usefulness with a precision up to a few centimeters, and will most likely also be useful for terrain images obtained from the UAV system from low heights up to $60 \mathrm{~m}$ for such anthropogenic geotechnical formations. Laboratory and small scale field tests carried out on the possibility of replacing 3D scanners with $2 \mathrm{D}$ scanners have demonstrated the usefulness of the latter in the case of the ability to ensure uniform movement of such systems horizontally in the cross-machine direction even without the use of positioning systems. The key here is the ability to evenly move the scanning device head. The UAV system is now available for such a possibility. The inertial positioning system was used to determine the time of the measurement. The reaction of the measuring system to changes in the direction of movement were tested. A system of artificially placed benchmarks was also used for testing. The system of such well-visible from the air reference benchmarks can be particularly useful for verification of images obtained by multiple passes, also at longer intervals. At difficult geometrical conditions (for deep anthropogenic forms) requiring changes in the flight altitude of UAV systems, it will be necessary use fully developed spatial orientation systems such as on-board inertial sensors, including GPS.

\section{References}

1. Kowalski A., Deformacje powierzchni w Górnośląskim Zagłębiu Węglowym, GIG, Katowice (2015).

2. Didier Ch., Merwe N., Betourney M., Mainz M., Kotyrba A., Aydan Ö., Jossien J.P., Song W.K., Mine closure and post - mining management, International State of the Art. ISRM Mine Closure Commission Report (CD) (2008).

3. Kotyrba A., Wiadomości Górnicze, 7-8 (2005).

4. Pilecki Z., Kotyrba A., Prace naukowe GIG, Górnictwo i Środowisko, wydanie special edition No.III (2007).

5. Hamerla A., Pierzchała Ł., Inżynieria Ekologiczna (to be published)

6. Kogut J. P, Pilecka E., Szwarkowski D., Civil and Environmental Engineering Reports 28, 2 (2018)

7. Kotyrba A., Frolik A., Siwek S., Zeszyty Naukowe Instytutu Gospodarki Surowcami Mineralnymi i Energią PAN, 10 (2016)

8. Motyka Z., JCEEA-64-02-t2 (2017)

9. Szade A., Bartmański C., Ramowski A, MAM (2016). 
10. Motyka Z., Wiadomości Górnicze, 9 (2016).

11. Smoła T., Motyka Z., Szade A., Ramowski A., BUP, 1106, 11 (2016).

12. Passia H., Smoła T, Szade A., Ramowski A., Przegląd Górniczy, 6 (2016). 